\title{
Erratum to: Distilling the essence of appraisal: a mixed methods study of people with multiple sclerosis
}

\author{
Bruce D. Rapkin ${ }^{1}$ Carolyn E. Schwartz ${ }^{2,3}$
}

Published online: 19 March 2016

(c) Springer International Publishing Switzerland 2016

\section{Erratum to: Qual Life Res DOI 10.1007/s11136-015-1119-z}

In the original publication of the article, there were some errors in the table and contents which are mentioned as follows:

The term "expected" has been added to Table 2 legend, which now reads "Table 2. Significant correlations of appraisal measures with discriminant functions distinguishing groups with different levels of expected QOL" (Table 2).

The term "residual" has been added to Table 3 legend, which now reads "Table 3. Significant correlations of appraisal measures with discriminant functions distinguishing groups with different levels of residual QOL" (Table 3).

The online version of the original article can be found under doi:10.1007/s11136-015-1119-z.

Electronic supplementary material The online version of this article (doi:10.1007/s11136-016-1253-2) contains supplementary material, which is available to authorized users.

Carolyn E. Schwartz

carolyn.schwartz@deltaquest.org

1 Department of Epidemiology and Population Health, Division of Community Collaboration and Implementation Science, Albert Einstein College of Medicine, Bronx, NY, USA

2 DeltaQuest Foundation, Inc., 31 Mitchell Road, Concord, MA 01742, USA

3 Departments of Medicine and Orthopaedic Surgery, Tufts University Medical School, Boston, MA, USA
The row "recent experiences" has been removed from Table 3, and values have been inserted in the row "flare-ups". Table 4 content:

The following text that was cut off from the row PSSUM_EXP2 in the online paper has now been added: "Focus on future achieving goals, seriousness of the situation, and worries regarding relationships".

The row MCS_RES2 had incorrect content in the online paper, and the following text has now been included: "Work and unemployment, long-term concerns, not big changes, and not to emphasize the positive" (Table 4).

Manuscript text page 13 has been changed to reflect the abovementioned changes to Table 3 content as follows (changes noted in bold):

The discriminant function analysis examined more closely how appraisal variables combined to influence residual variation in reports of functioning. Discriminant Function 1 distinguished the groups with better and worse-than-expected ratings, while Function 2 reflected the average versus extreme groups (Supplemental Figure 1b). High scores on Function 1 were characterized by a tendency to recall and sample recent flare-ups and serious concerns when responding to questions about QOL and by a focus on help needed and difficulties, and a tendency to compare oneself to a time before MS. Function 1 was also related to personal goals involving independent functioning and goals pertaining to MS. Conversely, mention of goals regarding one's self-image and personality was negatively correlated with this Function. Function 2 was dominated by a distinction among those who articulated more personal goals about MS versus those whose goals were concerned with mental health and mood. This function also indicates recollection of recent flare-ups versus thinking about relationships and an emphasis on how well one is doing. 


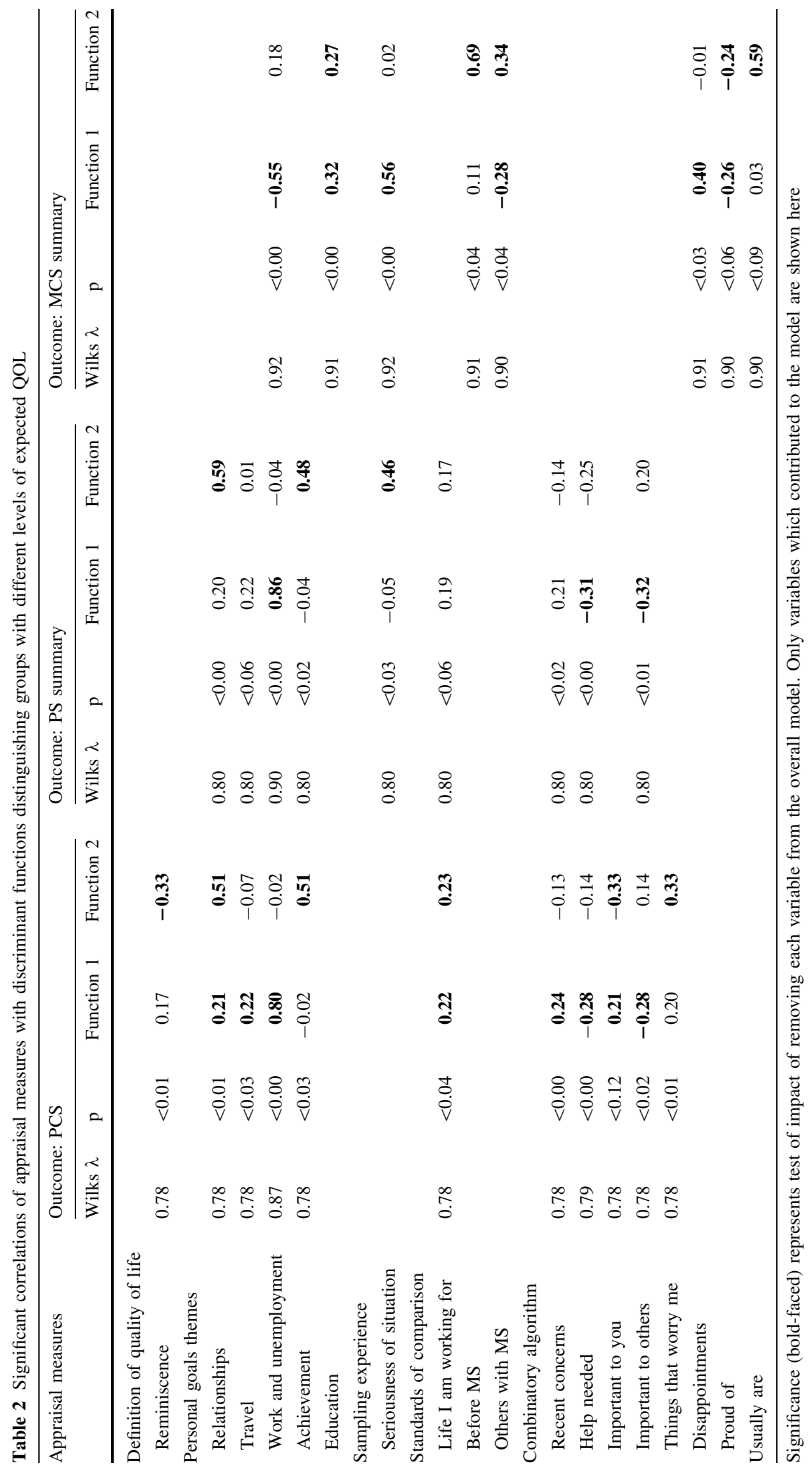




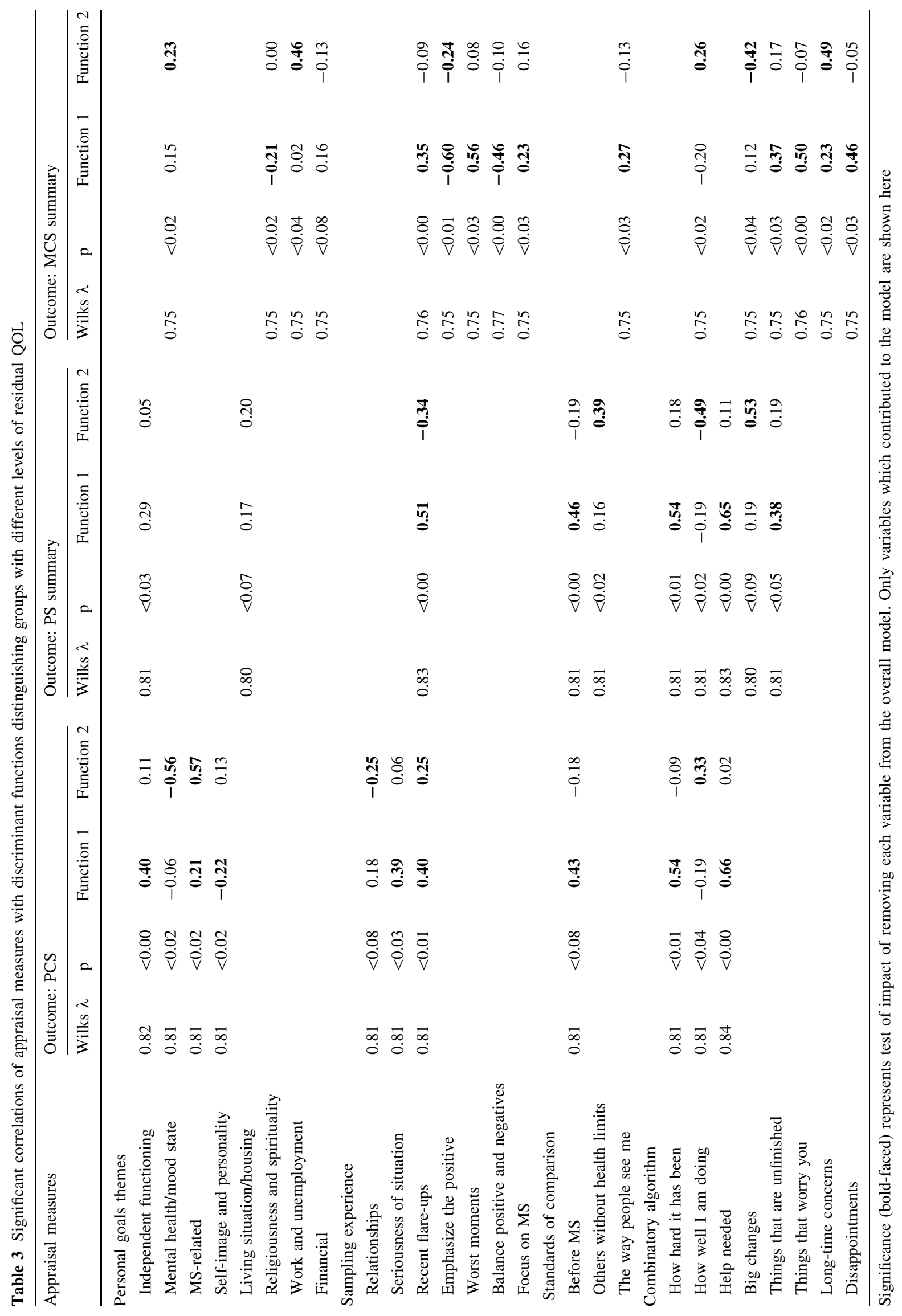


Table 4 Characterizing the appraisal profiles based on discriminant function analyses

\begin{tabular}{lll}
\hline Discriminant Function & Poor & Stable versus Problem- \\
versus volatile & focused \\
good & versus \\
emotion- & focused
\end{tabular}

PCS_EXP1

Oriented toward work-related issues with low concerns about getting help from others PCS_EXP2

Focus on future achieving goals and worries regarding relationships, not reminiscing PSSUM_EXP1

Same as PCS EXP1

$\mathrm{X}$

$\mathrm{X} \quad \mathrm{X}$

PSSUM_EXP2

Focus on future achieving goals, seriousness of the situation, and worries regarding relationships

MCS_EXP1

Serious problems, disappointments with low concerns about positive accomplishments in light of MS

MCS_EXP2

Dwelling on MS

PCS_RES1

Difficulties and help needed to maintain independence, compared to before MS

PCS_RES2

Focus on doing well with MS at present with low concerns about mood and relationships (like problemfocused versus emotion-focused coping)

PSSUM_RES1

Help needed with recent flare-ups and difficulties, compared to before MS PSSUM_RES2

Big changes relative to others without health limits compared to focusing on how well managing recent $\mathrm{x}$ symptom changes

MCS_RES1

Focus on worries and disappointments re: MS; not focused on positive balance

MCS_RES2

Work and unemployment, long-term concerns, not big changes, and not to emphasize the positive

$\mathrm{x}$

Supplementary text file as shown in the online version had the Track Changes mode. All changes have been accepted so that the final version is now available.
However, the corrected tables and corrections are included in this erratum. 